DOI: 10.12731/wsd-2017-4-2-137-149

УДК 582.572.8 (470.47)

\title{
СЕМЕННАЯ ПРОДУКТИВНОСТЬ РАСТЕНИЙ В ЦЕНОПОПУЛЯЦИЯХ TULIPA ВIFLORA В УСЛОВИЯХ РЕСПУБЛИКИ КАЛМЫКИЯ
}

\section{Очирова А.С., Головкова А.М., Овадыкова Ж.В., Лиджиева Н.Ц.}

Цель. Жизнеспособные семена в составе популяиий рассматриваются как показатель жизненной стратегии видов. Отсюда семенную продуктивность можно рассматривать как важный показатель адаптированности видов условиям местообитания. Семенная продуктивность луковичных эфемероидов, произрастаюших в аридных условиях, изучена не достаточно. В связи с вышесказанным иелью нашего исследования было выявление семенной продуктивности растений в иенопопуляциях тюльпана двуцвветкового - Tulipa biflora Pall. (Liliaceae), рекомендованного в условиях Калмыкии к охране.

Материалы и методы. Исследовано три ценопопуляиии Tulipa biflora в составе разных растительных сообществ на бурых легкосуглинистых солониеватых почвах. Объем выборки составлял не менее 30 растений Tulipa biflora, y зрельх плодов которых учитывали мерные признаки и выявляли потенциальную и фактическую семенную продуктивность, а также процент семинификации. Плотность генеративных растений учитывали на 10 участках 0,5 кв. м, расположенных по трансекте.

Результаты. Биометрические признаки плода у растений в популяичих Tulipa biflora были положительно скоррелированы с температурой воздуха в период активной вегетаиии вида.

Потенииальная и фактическая семенная продуктивность растений в ценопопуляииях Tulipa biflora в 2017 году больше, чем в 2016 году, однако по проценту семинификации отмечали обратные результаты: в 2017 году он был на 4,7-10,4\% ниже. При этом растения одной из иенопопулящий Tulipa biflora, обнаружили в оба года исследования наибольший проиент семинификачии: в 2016 году - 77,5, в 2017 году - 67,1 шт. семян на растение.

Банк зрельх семян, который формируется в течение вегетационного сезона в иеенопопуляциях Tulipa biflora, составил в годы исследования в среднем 782,8-1338,4 семян на 1,0 кв.м. 
Заключение. Получено представление о банке зрелых семян-782,81338, 4 семян на 1,0 кв.м, который формируется в ценопопуляциях Tuliра biflora в течение вегетационного сезона, составляя репродуктивный потенциал для их возобновления в аридных условиях Республики Калмыкия.

Ключевые слова: тюльпан двуцветковый; иченопопуляция; семенная продуктивность; банк семян.

\section{THE SEED PRODUCTIVITY OF PLANTS IN CENOPOPULATION TULIPA BIFLORA UNDER THE CONDITIONS OF THE REPUBLIC OF KALMYKIA}

\section{Ochirova A.S., Golovkova A.M., Ovadikova J.V., Lidjieva N.C.}

Background: Viable seeds in the composition of populations are considered as an indicator of the life strategy of species. Hence, seed productivity can be considered as an important indicator of species adaptation to habitat conditions. The replaceable productivity of bulbous ephemeroids growing in arid conditions has not been studied sufficiently. In connection with the foregoing, our goal was to identify the seed productivity of plants in the tulip cenopopulations of the two-flowered tulip - Tulipa biflora Pall. (Liliaceae), which is recommended for protection in the conditions of Kalmykia.

Materials and metods: Three cenopopulations of Tulipa biflora were studied in different plant communities on brown light loamy solonetzic soils. The sample size was no less than 30 plants of Tulipa biflora, their mature fruits were considered in the aspects of the measured features, their potential and actual seed production, as well as the percentage of seminification. The density of generative plants was taken into account at 10 sites of 0.5 square meters, located along the transect.

Resalts: Biometric signs of the fetus in plants in Tulipa biflora populations were positively correlated with air temperature during the active vegetation period of the species.

The potential and actual seed productivity of plants in the Tulipa biflora cenpopulations in 2017 is more than in 2016, however, the percentage of seminification marked the reverse results: in 2017 it was 4.7-10.4\% lower. In this case, the plants of one of the Tulipa biflora cenopopulations, showed the great- 
est percentage of seminification in both studies: in 2016-77.5, in 2017-67.1 pieces of seeds per plant.

The mature seed bank which is formed during the growing season in the cenopopulations of Tulipa biflora during the years under the study amounted to 782.8-1338.4 seeds per 1.0 sq.m.

Conclusion: The idea of a bank of mature seeds was got-782.8-1338.4 seeds per $1.0 \mathrm{~m} 2$, which is formed in the Tulipa biflora cenopopulations during the growing season, making up the reproductive potential for their renewal in the arid conditions of the Republic of Kalmykia.

Keywords: tulip two-flowered; cenopopulation; seed productivity; seed bank.

Характер возобновления растений разных видов, составляющих растительное сообщество играет важное значение для раскрытия разных сторон его формирования. В то же время жизнеспособные семена в составе ценотических популяций рассматриваются как показатель жизненной стратегии видов [1-5] и, несомненно, важна их в эволюции популяций растений [6]. Отсюда семенную продуктивность можно рассматривать как важный показатель адаптированности видов к условиям местообитания. В связи с вышесказанным целью нашего исследования было выявление семенной продуктивности растений в ценопопуляциях тюльпана двуцветкового - Tulipa biflora Pall. (Liliaceae). Вид занесен в Красную книгу Республики Калмыкия с категорией редкости III - «редкий вид» [7]. Из видов тюльпанов во флоре Калмыкии данный вид наиболее ранний «первоцвет» и его цветение приходится на конец марта - начало апреля. В Республике Калмыкия начато изучение структуры популяций видов тюльпанов [8-10].

Объектами исследования были три ценопопуляции Tulipa biflora в Прикаспийской низменности (в пределах Республики Калмыкия). Ценопопуляция «Хулхута» произрастала в составе луковичномятликово-полынного (Artemisia lercheana - Artemisia santonica - Poa bulbosa) сообщества, ценопопуляция «Чомпот» - разнотравно-луковичномятликово-полынного (Artemisia - Poa bulbosa-Mixteherbosa) сообщества и ценопопуляция «Цаган-Аман» - луковичномятликово-лерхополынного (Artemisia lercheana Poa bulbosa) сообщества на бурых легкосуглинистых солонцеватых почвах. Материалом для исследования 30 растений Tulipa biflora, у зрелых плодов которых учитывали мерные признаки - длину (мм) и ширину (мм) плода и выявляли потенциальную семенную продуктивность как общее количество семязачатков в цветке, а затем в коробочке и фактическую семенную 
продуктивность как количество сформированных созревших семян в коробочке [11]. Кроме того во всех исследованных ценопопуляциях выявляли плотность генеративных растений на 0,25 кв.м, произведя учет растений на 10 участках 0,5 кв. м, расположенных по трансекте. Полученные данные были далее подвергнуты перерасчету на 1 кв.м.

Формирование плодов и семян, по-видимому, в некоторой степени зависит от погодных условий, складывающихся в период активной вегетации растений. За март-апрель в 2017 году объем осадков значительно больше по сравнению с предыдущим годом, а температура воздуха в марте - на 1,0-2, $6^{\circ} \mathrm{C}$ ниже (табл. 1 ).

Таблииа 1.

Погодные условия в местах произрастания Tulipa biflora в период исследования

\begin{tabular}{|c|c|c|c|c|c|c|c|c|}
\hline \multirow{2}{*}{$\begin{array}{c}\text { Цено- } \\
\text { популяция }\end{array}$} & \multicolumn{4}{|c|}{2016 год } & \multicolumn{4}{c|}{2017 год } \\
\cline { 2 - 9 } & \multicolumn{2}{|c|}{$\begin{array}{c}\text { Сумма } \\
\text { осадков, мм }\end{array}$} & \multicolumn{2}{c|}{$\begin{array}{c}\text { Средне- } \\
\text { месячная } \mathrm{t}^{0}\end{array}$} & \multicolumn{2}{c|}{$\begin{array}{c}\text { Сумма } \\
\text { осадков, мм }\end{array}$} & \multicolumn{2}{c|}{$\begin{array}{c}\text { Средне- } \\
\text { месячная } \mathrm{t}^{0}\end{array}$} \\
\hline & март & апрель & март & апрель & март & апрель & март & апрель \\
\hline Хулхута & 16,0 & 15,2 & 6,8 & 14,7 & 26,7 & 17,8 & 5,8 & 12,1 \\
\hline Чомпот & 37,9 & 31,3 & 6,1 & 14,3 & 37,0 & 32,1 & 5,0 & 11,8 \\
\hline Цаган-Аман & 30,9 & 28,6 & 5,7 & 14,0 & 40,0 & 33,8 & 4,6 & 11,7 \\
\hline
\end{tabular}

При изучении биометрических признаков плода Tulipa biflora показано, что у зрелой коробочки значения ее длины и ширины близки даже ширина незначительно, но больше длины. Анализ параметров плода у растений в ценопопуляциях Tulipa biflora выявил, что в оба года исследований в ценопопуляции «Хулхута» они больше, чем в двух других исследованных ценопопуляциях. Так в 2016 году длина коробочки у растений в данной ценопопуляции была больше по сравнению с ценопопуляцией «Чомпот» на 2,2 мм $\left(\mathrm{t}_{\text {diff }}=4,38\right.$, при $\left.\mathrm{P}<0,05\right)$, с ценопопуляцией «Цаган-Аман» - на 3,4 мм ( $\mathrm{t}_{\text {diff }}=5,98$, при $\left.\mathrm{P}<0,01\right)$ (табл. 2). Порядок ценопопуляций по мере уменьшения параметров плода был следующим: ЦП «Хулхута» ${ }^{\circledR}$ ЦП «Чомпот» ${ }^{\circledR}$ ЦП «Цаган-Аман». При этом во всех исследованных ценопопуляциях в 2017 году размеры коробочек у растений Tulipa biflora больше, чем в 2016 году.

Семенная продуктивность меньше зависела от погодных условий, проявив специфическую изменчивость в ценопопуляциях Tulipa biflora. В 2016 году потенциальная семенная продуктивность в исследованных ценопопуляциях варьировала от 39,6 шт. семян в ценопопуляции «Цаган-Аман» до 68,0 шт. семян в ценопопуляции «Чомпот». В следующем 
году данные ценопопуляции также имели наибольшее и наименьшее значения, однако различия между ценопопуляциями в этот год менее существенны. В то же время, во всех исследованных ценопопуляциях потенциальная семенная продуктивность в 2017 году значительно выше, чем в 2016 году: в ценопопуляции «Хулхута» - на 30, 1 шт. семян $\left(\mathrm{t}_{\text {diff }}=\right.$ $4,34$, при $\mathrm{P}<0,05)$, в ценопопуляции «Чомпот» - на 16,0 шт. семян $\left(\mathrm{t}_{\text {diff }}=\right.$ $2,67$, при $\mathrm{P}<0,05)$, в ценопопуляции «Цаган-Аман» - на 30,2 шт. семян $\left(\mathrm{t}_{\text {diff }}=6,38\right.$, при $\left.\mathrm{P}<0,05\right)$ (табл. 3).

Таблица 2.

Параметры плода растений в ценопопуляциях Tulipa biflora

\begin{tabular}{|c|c|c|c|}
\hline \multirow[b]{2}{*}{ Ценопопуляция } & \multirow[b]{2}{*}{ Год } & Длина плода, мм & Ширина плода, мм \\
\hline & & $\frac{\overline{\mathrm{x}} \pm \mathrm{S}_{\overline{\mathrm{x}}}}{\mathrm{C}_{\mathrm{v}}}$ & $\frac{\overline{\mathrm{x}} \pm \mathrm{S}_{\overline{\mathrm{x}}}}{\mathrm{C}_{\mathrm{v}}}$ \\
\hline \multirow{2}{*}{ Хулхута } & 2016 & $\frac{13,7 \pm 0,36}{10,4}$ & $\frac{13,9 \pm 0,40}{11,5}$ \\
\hline & 2017 & $\frac{13,7 \pm 0,29}{11,9}$ & $\frac{13,9 \pm 0,29}{12,0}$ \\
\hline \multirow{2}{*}{ Чомпот } & 2016 & $\frac{11,5 \pm 0,35}{17,5}$ & $\frac{12,9 \pm 0,45}{20,3}$ \\
\hline & 2017 & $\frac{13,3 \pm 0,39}{16,2}$ & $\frac{13,6 \pm 0,39}{15,1}$ \\
\hline \multirow{2}{*}{ Цаган-Аман } & 2016 & $\frac{10,3 \pm 0,44}{20,5}$ & $\frac{11,3 \pm 0,40}{16,9}$ \\
\hline & 2017 & $\frac{12,8 \pm 0,36}{15,3}$ & $\frac{13,2 \pm 0,31}{16,6}$ \\
\hline
\end{tabular}

При изучении фактической семенной продуктивности много абортивных семян с несформированным зародышем отмечали ближе к вершине и основанию плода Tulipa biflora. Это согласуется с данными литературы для других видов из рода Tulipa $[12,13]$. По-видимому, это является одной из причин того, что фактическая семенная продуктивность существенно ниже потенциальной семенной продуктивности и ее значения колеблются в больших пределах. Это нашло отражение в больших значениях коэффициента вариации фактической семенной продуктивности в оба года исследования во всех изучаемых ценопопуляциях. Фактическая семенная продуктивность в ценопопуляциях Tulipa biflora изменялась в годы исследования подобно потенциальной семенной продуктивности. Наибольшую фактическую семенную продуктивность отмечали в цено- 
популяции «Чомпот» - 52,7-56,4 шт. семян на растение, наименьшую - в ценопопуляции «Цаган-Аман» - 24,6-43,7 шт. семян на растение. Значение данного показателя в ценопопуляциях Tulipa biflora в 2017 году значительно больше, чем в 2016 году. Особенно большую разницу в отношении фактической семенной продуктивности по годам равную 17,1 шт. семян на растение отмечали в ценопопуляции «Цаган-Аман» $\left(\mathrm{t}_{\text {diff }}=\right.$ $4,03$, при $\mathrm{P}<0,05)$. Однако, несмотря на увеличение показателей семенной продуктивности в 2017 году по сравнению с 2016 годом, процент семенификации в 2017 году ниже, чем в 2016 году.

Таблица 3.

Семенная продуктивность растений в ценопопуляциях Tulipa biflora

\begin{tabular}{|c|c|c|c|c|}
\hline \multirow[t]{2}{*}{ Ценопопуляция } & \multirow[t]{2}{*}{ Год } & $\begin{array}{c}\text { Потенциальная } \\
\text { семенная продук- } \\
\text { тивность, шт. }\end{array}$ & $\begin{array}{c}\text { Фактическая се- } \\
\text { менная продуктив- } \\
\text { ность, шт. }\end{array}$ & \multirow{2}{*}{$\begin{array}{l}\text { Процент } \\
\text { семени- } \\
\text { фикации }\end{array}$} \\
\hline & & $\frac{\overline{\mathrm{x}} \pm \mathrm{S}_{\overline{\mathrm{x}}}}{\mathrm{C}_{\mathrm{v}}}$ & $\frac{\overline{\mathrm{x}} \pm \mathrm{S}_{\overline{\mathrm{x}}}}{\mathrm{C}_{\mathrm{v}}}$ & \\
\hline \multirow{2}{*}{ Хулхута } & 2016 & $\frac{50,6 \pm 6,49}{42,5}$ & $\frac{32,9 \pm 5,29}{53,3}$ & 65,0 \\
\hline & 2017 & $\frac{80,7 \pm 2,47}{17,3}$ & $\frac{46,3 \pm 2,81}{34,3}$ & 57,4 \\
\hline \multirow{2}{*}{ Чомпот } & 2016 & $\frac{68,0 \pm 5,04}{40,7}$ & $\frac{52,7 \pm 4,66}{48,4}$ & 77,5 \\
\hline & 2017 & $\frac{84,0 \pm 3,27}{21,3}$ & $\frac{56,4 \pm 3,62}{35,1}$ & 67,1 \\
\hline \multirow{2}{*}{ Цаган-Аман } & 2016 & $\frac{39,3 \pm 3,95}{48,3}$ & $\frac{26,6 \pm 3,06}{55,2}$ & 67,7 \\
\hline & 2017 & $\frac{69,5 \pm 2,61}{20,6}$ & $\frac{43,7 \pm 2,94}{36,9}$ & 63,0 \\
\hline
\end{tabular}

Процент семенификации в ценопопуляции Tulipa biflora в 2016 году варьировал от 65,0 до 77,5\%, в 2017 году изменялся от 57,4 до $67,1 \%$. Соглашаясь с мнением ряда авторов $[11,14,15]$ полагаем, что ценопопуляция «Чомпот», обнаружившая в оба года исследования наибольший процент семенификации, находится в таких экологических условиях, которые максимально соответствуют биологическим потребностям вида.

Для определения банка семян, который формируется в природных популяциях в нашей работе был произведен учет числа генеративных растений [16-20] на 0,5 х 0,5 кв.м. Поскольку вид является луковичным эфемероидом, то можно полагать, что все ресурсы луковицы затрачи- 
ваются на формирование репродуктивных органов и на следующий год возобновление растения не всегда сопровождается формированием цветущего растения. В нашей работе в ценопопуляции «Хулхута», в которой в 2016 году отмечали наибольшее среднее число генеративных растений 7,0 особей на 0,25 кв.м., на следующий год оно было наименьшим; в то время как ценопопуляция «Чомпот», которая в 2016 году имела наименьшее среднее число генеративных растений, в 2017 году оно было максимальным и составило 9,1 особей на 0,25 кв.м (рис. 1 ).

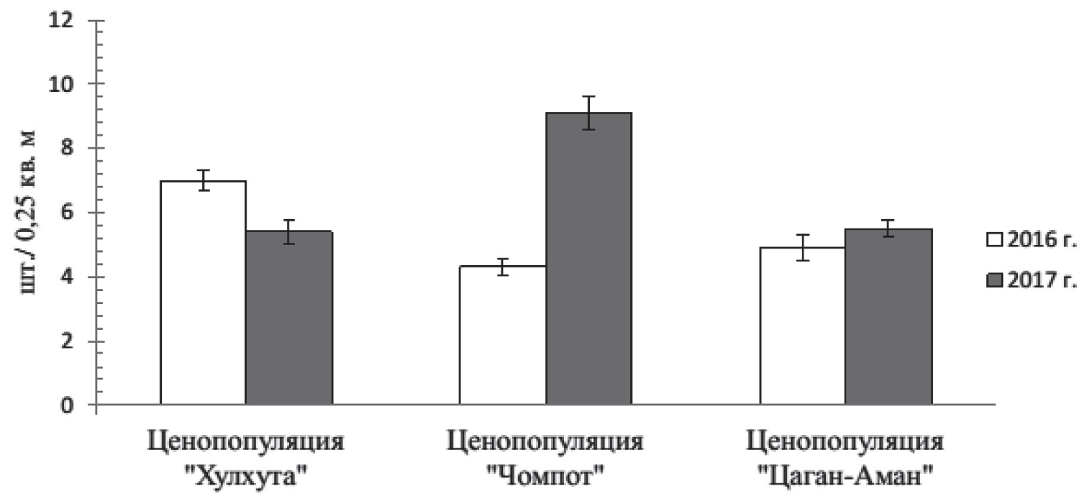

Рис. 1. Плотность растений генеративного возрастного состояния (на 0,25 кв.м.) в ценопопуляциях Tulipa biflora

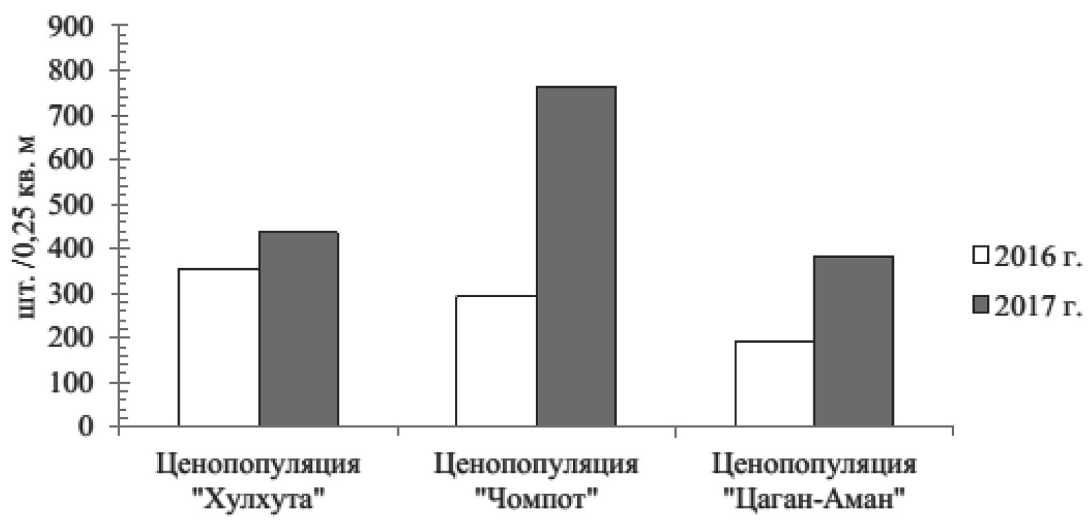

Рис. 2. Потенциальный резерв семян в ценопопуляциях Tulipa biflora 
Данные о плотности генеративных растений и семенной продуктивности были использованы для определения потенциального резерва семян, формирующегося в природных популяциях Tulipa biflora. Потенциальный банк зрелых семян в ценопопуляциях Tulipa biflora в 2016 году варьировал от 130,3 семян на 0,25 кв.м в ценопопуляции «Цаган-Аман» до 230,3 семян на 0,25 кв.м в ценопопуляции «Хулхута», составив в среднем 195,7 семян на 0,25 кв.м (рис. 2).

В 2017 году потенциальный резерв зрелых семян в природных популяциях Tulipa biflora был значительно больше - 334,6 семян на 0,25 кв.м.

\section{Заключение}

Получено представление о банке зрелых семян - 782,8-1338,4 семян на 1,0 кв.м, который формируется в ценопопуляциях Tulipa biflora в течение вегетационного сезона, составляя репродуктивный потенциал для их возобновления в аридных условиях Республики Калмыкия.

\section{Список литературы}

1. Grubb P.J. A theoretical background to the conservation of ecologically distinct groups of annuals and biennials in the chalk grassland ecosystem // Biol. Conserv. 1976, vol. 10, no. 1, pp. 53-76.

2. Работнов Т.А. Жизнеспосбные семена в составе ценотических популяций как показатель стратегии жизни видов растений // Бюлл.МОИП. Отд. биол. 1981. Т. 86. № 3 С. $68-78$.

3. Grime J.P., Mason G., Curtis A.V., Rodman J., Band S.R., Mowforth M.A.G., Neal A.M., Shaw S. A comparative study of germination characteristics in a local flora // J. Ecol. 1981, vol. 69, no. 3, pp. 1017-1059.

4. Gross K.L., Werner P.A. Colonizing abilities of «biennial» plant species in relation to ground cover: implications for their distributions in a successional sere // Ecology. 1982, vol. 63, no. 4, pp. 921-931.

5. During H.J., Schenkeveld A.J., Verkaar H.J., Willems J.H. Demography of short-lived forbs in chalk grassland in relation to vegetation structure // The Population Structure of Vegetation. Handbook of Vegetation Science. 1985, vol. 3, pp. 341-370.

6. Cook R. The biology of seeds in the soil // Demography and evolution in plant populations. Oxsford, 1980, pp. 107-129.

7. Красная книга Республики Калмыкия: в 2 т. Редкие и находящиеся под угрозой исчезновения растения и грибы / отв. ред. Н.М. Бакташева. Элиста: ЗАОр «НПП «Джангар», 2014. Т.2. 199 с. 
8. Изменчивость морфологической структуры растений в ценопопуляциях Tulipa biebersteiniana в заповеднике «Черные земли» / Лыу Т.Н., Лиджиева Н.Ц., Очирова А.С., Кондышев О.Ю. // В мире научных открытий. Красноярск, 2015а. № 10 (70). С. 84-90.

9. Фитоценотическая приуроченность Tulipa biflora в государственном природном биосферном заповеднике «Черные земли» / Лыу Т.Н., Очирова А.С., Лиджиева Н.Ц., Овадыкова Ж.В. // Научная мысль Кавказа. 20156. № 4 (84). C. 115-119.

10. Лыу Т.Н., Очирова А.С., Лиджиева Н.Ц. Изменчивость морфологических признаков растений и виталитетная структура ценопопуляций видов рода Tulipa (Liliaceae) в заповеднике «Черные земли» // Известия Самарского научного центра Российской академии наук. 2016. Т. 18. № 5 (2). С. 314-319.

11. Вайнагий И.В. О методике изучения семенной продуктивности растений // Бот. журн. 1974. Т. 59. №. 6. С. 826-831.

12. Муллабаева А.Р., Муллабаева Э.З. Некоторые результаты исследования Tulipa biebersteiniana на хребте Ирандык // Охрана и рациональное использование природных ресурсов в Башкирском Зауралье. Уфа: РИО БашГУ, 2006.

13. Сулейманова А.А. Семенная продуктивность Tulipa patens agardh ex schult. et schult. fil. в условиях Башкирского Зауралья // Научные исследования в современном мире: проблемы, перспективы, вызовы. Матер. II Междунар. мол. науч. конф. Часть I. Уфа: БашГАУ, 2012. С. 243-246.

14. Вирачева Л.Л. Значение элементов семенной продуктивности для характеристики поведения растений // Ботанические исследования в Субарктике. Апатиты, 1974. С. 186-194.

15. Тюрина Е.В. Семенная продуктивность и коэффициент семенификации сибирских видов рода горичник // Тезисы доклада IV Всес. совещ. по семеноводству и семеноведению интродуцентов. Новосибирск, 1974. C. $102-104$.

16. Работнов Т.А. Жизненный цикл многолетних травянистых растений в луговых ценозах // Геоботаника. М. Л.: Труды Бот. ин-та им. В.Л. Комарова АН СССР. 1950a. Сер. ІІІ. Вып. 6. С. 7-197.

17. Уранов А.А. Жизненное состояние вида в растительном сообществе // Бюл. МОИП. Отделение биол. 1960. Т. 65. Вып. 3. С. 77-92.

18. Уранов А.А. Онтогенез и возрастной состав популяций // Онтогенез и возрастной состав популяций цветковых растений. М.: Наука, 1967. С. 3-8.

19. Ценопопуляции растений (основные понятия и структура) / Отв. ред. А.А. Уранов, Т.И. Серебрякова. М.: Наука, 1976. 217 с. 
20. Ценопопуляций растений / Отв. ред. Т.И. Серебрякова. М.: Наука, 1977. $173 \mathrm{c}$.

\section{References}

1. Grubb P.J. A theoretical background to the conservation of ecologically distinct groups of annuals and biennials in the chalk grassland ecosystem. Biol. Conserv., 1976, vol. 10, no. 1, pp. 53-76.

2. Rabotnov T.A. Zhiznesposbnye semena v sostave tsenoticheskikh populyatsiy kak pokazatel' strategii zhizni vidov rasteniy [Viable seeds in the composition of cenotic populations as an indicator of the life strategy of plant species]. Byull.MOIP. Otd. Boil [Bull. of the MOIP. Ser.of Biology]. 1981. Vol. 86. № 3, pp. 68-78.

3. Grime J.P., Mason G., Curtis A.V., Rodman J., Band S.R., Mowforth M.A.G., Neal A.M., Shaw S. A comparative study of germination characteristics in a local flora. J. Ecol. 1981. vol. 69, no. 3, pp. 1017-1059.

4. Gross K.L., Werner P.A. Colonizing abilities of «biennial» plant species in relation to ground cover: implications for their distributions in a successional sere. Ecology, 1982, vol. 63, no. 4, pp. 921-931.

5. During H.J., Schenkeveld A.J., Verkaar H.J., Willems J.H. Demography of short-lived forbs in chalk grassland in relation to vegetation structure. The Population Structure of Vegetation. Handbook of Vegetation Science, 1985, vol. 3, pp. 341-370.

6. Cook R. The biology of seeds in the soil. Demography and evolution of plant populations. Oxsford, 1980, pp. 107-129.

7. Krasnaya kniga Respubliki Kalmykiya: v 2 t. Redkie i nakhodyashchiesya pod ugrozoy ischeznoveniya rasteniya $i$ griby [The Red Book of the Republic of Kalmykia: in 2 vol. Rare and endangered plants and mushrooms]. Elista: ZAOr «SPE «Dzhangar», 2014. Vol.2. 199 p.

8. Lyu T.N., Lidzhieva N.Ts., Ochirova A.S., Kondyshev O.Yu. Izmenchivost' morfologicheskoy struktury rasteniy $\mathrm{v}$ tsenopopulyatsiyakh Tulipa biebersteiniana v zapovednike «Chernye zemli» [Variability of morphological structure of plants in Tulipa biebersteiniana populations in the nature reserve «Black soil»]. V mire nauchnykh otkrytiy [In the World of Scientific Discoveries]. Krasnoyarsk, 2015a. № 10 (70), pp. 84-90.

9. Lyu T.N., Ochirova A.S., Lidzhieva N.Ts., Ovadykova Zh.V. Fitotsenoticheskaya priurochennost' Tulipa biflora $\mathrm{v}$ gosudarstvennom prirodnom biosfernom zapovednike «Chernye zemli» [Phytocenotic Confinement of Tulipa biflora in State Nature Biosphere Reserve «Black soil»]. Nauchnaya mysl' Kavkaza [Scientific Thought of Caucasus]. 2015b. № 4 (84), pp. 115-119. 
10. Lyu T.N., Ochirova A.S., Lidzhieva N.Ts. Izmenchivost' morfologicheskikh priznakov rasteniy i vitalitetnaya struktura tsenopopulyatsiy vidov roda Tulipa (Liliaceae) v zapovednike «Chernye zemli» [The variability of morphological features in plants and vitality structure of cenopopulations of species of genus Tulipa (Liliaceae) in the natural reserve «The Black soil»]. Izvestiya Samarskogo nauchnogo tsentra Rossiyskoy akademii nauk [Izvestiya of the Samara Scientific Center of the Russian Academy of Sciences]. 2016. Vol. 18. № 5 (2), pp. 314-319.

11. Vaynagiy I.V. O metodike izucheniya semennoy produktivnosti rasteniy [On the method of studying the seed productivity of plants]. Bot. zhurn. [Botanical Journal]. 1974. Vol. 59. №. 6, pp. 826-831.

12. Mullabaeva A.R., Mullabaeva E.Z. Nekotorye rezul'taty issledovaniya Tulipa biebersteiniana na khrebte Irandyk [Some results of the Tulipa biebersteiniana study on the ridge of Irandik]. Okhrana i ratsional'noe ispol'zovanie prirodnykh resursov $v$ Bashkirskom Zaural'e [Protection and rational use of natural resources in the Bashkir Trans-Urals.]. Ufa: RIO BashGU, 2006.

13. Suleymanova A.A. Semennaya produktivnost' Tulipa patens agardh ex schult. et schult. fil v usloviyakh Bashkirskogo Zaural'ya [Seed productivity Tulipa patens agardh ex schult. et schult. fil. in conditions of the Bashkir TransUrals]. Nauchnye issledovaniya v sovremennom mire: problemy, perspektivy, vyzovy. Mater. II Mezhdunar. mol. nauch. konf. [Scientific research in the modern world: problems, prospects, challenges. Mather. II Intern. Mol. sci. Conf.]. Ufa: Bashkir State University, 2012. Part I, pp. 243-246.

14. Viracheva L.L. Znachenie elementov semennoy produktivnosti dlya kharakteristiki povedeniya rasteniy [The importance of elements of seed productivity for the behavior of plants]. Botanicheskie issledovaniya v Subarktike [Botanical studies in the Subarctic]. Apatity, 1974, pp. 186-194.

15. Tyurina E.V. Semennaya produktivnost' i koeffitsient semenifikatsii sibirskikh vidov roda gorichnik [Seed productivity and coefficient of semenification of Siberian species of the genus gorichnik]. Tezisy doklada IV Vses. soveshch. po semenovodstvu i semenovedeniyu introdutsentov [Abstracts of the IVth AllUnion meeting on Seed Production and Seed Research of introductions]. Novosibirsk, 1974, pp. 102-104.

16. Rabotnov T.A. Zhiznennyy tsikl mnogoletnikh travyanistykh rasteniy v lugovykh tsenozakh [The life cycle of perennial herbaceous plants in meadow cenoses]. Geobotanika [Geobotany]. M. L.: Proceedings of the Bot. Institute app. V.L. Komarova AS of the USSR. 1950a. ser. III. issue. 6, pp. 7-197.

17. Uranov A.A. Zhiznennoe sostoyanie vida $v$ rastitel'nom soobshchestve [The life condition of the species in the plant community]. Byul. MOIP. Otdelenie biol. [Bull. of the MOIP. Ser.of Biology]. 1960. Vol. 65. issue. 3, pp. 77-92. 
18. Uranov A.A. Ontogenez i vozrastnoy sostav populyatsiy [Ontogeny and age composition of populations]. Ontogenez $i$ vozrastnoy sostav populyatsiy tsvetkovykh rasteniy [Ontogeny and age composition of populations of flowering plants]. M.: Science, 1967, pp. 3-8.

19. Tsenopopulyatsii rasteniy (osnovnye ponyatiya i struktura) [Cenopopulation of plants (basic concepts and structure)]. M.: Science, 1976. 217 p.

20. Tsenopopulyatsiy rasteniy [Cenopopulation of plants]. M.: Science, 1977. 173 p.

\section{ДАННЫЕ ОБ АВТОРЕ}

Очирова Александра Сергеевна, аспирант

Федеральное государственное бюджетное общеобразовательное учреждение высшего образования «Калмыикий государственный университет имени Б.Б. Городовикова»

ул. Пушкина, 11. г. Элиста, 358009, Российская Федерация ochirowa.alex@yandex.ru

Головкова Анастасия Михайловна, магистрант

Федеральное государственное бюджетное общеобразовательное учреждение выстего образования "Калмыикий государственный университет имени Б.Б. Городовикова»

ул. Пушкина, 11. г. Элиста, 358009, Российская Федерация nast.golovkova2016@yandex.ru

Овадыкова Жанна Васильевна, к. с.-х. н., доцент кафедры метрологии, стандартизации и сертификации Федеральное государственное бюджетное образовательное учреждение выстего образования «Ухтинский государственный технический университет»

ул. Первомайская, 13. г. Ухта, 169300, Российская Федерация zhanna_ovadykova@mail.ru

Лиджиева Нина Цереновна, д.б.н., профессор, заведующий кафедрой общей биологии и физиологии

Федеральное государственное бюджетное общеобразовательное учреждение выстего образования «Калмыикий государственный университет имени Б.Б. Городовикова»

ул. Пушкина, 11. г. Элиста, 358009, Российская Федерачия for-lidjieva@yandex.ru 
DATA ABOUT THE AUTHORS

Ochirova Aleksandra Sergeevna, Postgraduate

Kalmyk State University named after B.B. Gorodovikova

11, Pushkin Str., Elista, 358009, Russian Federation

ochirowa.alex@yandex.ru

ORCID: 0000-0001-9924-3368

Golovkova Anastasiya Mikhaylovna, Graduate Student

Kalmyk State University named after B.B. Gorodovikova

11, Pushkin Str., Elista, 358009, Russian Federation

nast.golovkova2016@yandex.ru

ORCID: 0000-0002-4418-7052

Ovadykova Zhanna Vasil'evna, Candidate of Agriculture, Associate Professor of the Department of Metrology, Standardization and Certification Ukhta State Technical University

13, Pervomaiskaya Str., Ukhta, 169300, Russian Federation

zhanna_ovadykova@mail.ru

SPIN-code: 8079-8320

ORCID: 0000-0001-7539-6909

Lidzhieva Nina Tserenovna, Doctor of Biology, Professor, Head at the General Biology and Physiology Department

Kalmyk State University named after B.B. Gorodovikova

11, Pushkin Str., Elista, 358009, Russian Federation

for-lidjieva@yandex.ru

SPIN-code: -3661-2682

ORCID: 0000-0003-2668-698X 